NBER WORKING PAPER SERIES

\title{
PREDATION AND ACCUMULATION
}

\author{
Herschel I. Grossman \\ Minseong Kim
}

Working Paper 5357

\section{NATIONAL BUREAU OF ECONOMIC RESEARCH 1050 Massachusetts Avenue \\ Cambridge, MA 02138 \\ November 1995}

Minseong Kim acknowledges support from an Alfred P. Sloan Doctoral Dissertation Fellowship. We have received helpful suggestions from Oded Galor and In-Koo Cho. This paper is part of NBER's research programs in Economic Fluctuations and Growth. Any opinions expressed are those of the authors and not those of the National Bureau of Economic Research.

(C) 1995 by Herschel I. Grossman and Minseong Kim. All rights reserved. Short sections of text, not to exceed two paragraphs, may be quoted without explicit permission provided that full credit, including $(0)$ notice, is given to the source. 


\title{
PREDATION AND ACCUMULATION
}

\begin{abstract}
This paper incorporates the economic theory of predation into the theory of economic growth. The analytical framework is a dynamic general-equilibrium model of the interaction between two dynasties, one of which is a potential predator and the other is its prey. Each generation of each dynasty has to decide how to allocate its endowment of inherited wealth not only to consumption and productive capital, as in standard growth models, but also to either defensive fortifications or offensive weapons. Productive capital forms the basis for accumulation of wealth, but in each generation predation can cause both the destruction of wealth and a redistribution of wealth from the prey dynasty to the predator dynasty.

We find that, if the current wealth of the potential predator dynasty is small relative to the current wealth of the prey dynasty, then the current generation of the prey dynasty chooses to tolerate predation rather than to deter predation. We also find that over generations the security of the prey dynasty's property and the rate of accumulation of the prey dynasty's productive capital both steadily decrease, while the inherited wealth of the predator dynasty grows relative to the inherited wealth of the prey dynasty. Eventually, a generation of the prey dynasty will find that with predation its property would be so insecure that it is better off increasing its defensive fortifications sufficiently to deter predation.

Importantly, the relation between the security of the prey dynasty's property and its accumulation of productive capital, both of which are endogenous in the process of economic growth, is neither continuous nor monotonic. Generations of the prey dynasty that choose to deter predation, even though their property is perfectly secure, accumulate productive capital more slowly than the preceding generations that tolerated predation. Even if deterrence becomes a better choice for the prey dynasty than tolerating predation, deterrence is a costly choice.
\end{abstract}

Herschel I. Grossman

Department of Economics

Box B

Brown University

Providence, RI 02912

and NBER
Minseong Kim

Department of Economics

Box B

Brown University

Providence, RI 02912 
That wealth ... which always follows the improvements of agriculture and manu-

facture ... provokes the invasion of all their neighbors. An industrious, and upon

that account a wealthy nation, is of all nations the most likely to be attacked

...Adam Smith (1776, Book V, Chapter I, Part I).

Conventional wisdom holds that economic growth requires incentives to accumulate capital and that such incentives require, in turn, secure claims to the fruits of accumulation. But, surprisingly, economic analysis typically views predation and the resulting insecurity of property as depending only on political and other noneconomic factors and as exogenous to the process of resource accumulation. This view neglects the obvious fact that the security of property and the accumulation of productive capital both are endogenous in the process of economic growth.

This paper incorporates the economic theory of predation into the theory of economic growth. ${ }^{1}$ The analytical framework for this exercise is a dynamic general-equilibrium model of the interaction between two dynasties, one of which is a potential predator and the other is its prey. Each generation of each dynasty has to decide how to allocate its endowment of inherited wealth not only to consumption and productive capital, as in standard growth models, but also to either defensive fortifications or offensive weapons. Offensive weapons are the instruments of predation, whereas defensive fortifications serve either to deter predation or to mitigate the effects of predation. In each generation the accumulation of productive capital by each dynasty depends not only on that generation's allocation of inherited wealth to productive capital, but also on any redistribution and destruction of

\footnotetext{
${ }^{1}$ Examples of recent contributions to the literature on general equilibrium models of predation include Stergios Skaperdas (1992), Jack Hirshleifer (1995), and Herschel Grossman and Minseong Kim (1995). All of these papers abstract from economic growth. Several recent papers have presented empirical evidence that suggests that capital accumulation is positively related to the security of property rights, but these papers treat the security of property rights as exogenous. See, for example, Philip Keefer and Stephen Knack (1995), who also refer to various contributions to the literature. The present paper is also complementary to recent work on the political economy of economic growth - see, for example, Roberto Perotti (1992) and Alberto Alesina and Dani Rodrik (1994) - in which the government's tax and spending policies are both a cause and an effect of the growth of productive capacity, but which abstracts from predation as an economic activity.
} 
wealth that results from predation.

We use this analytical framework to address the following specific questions: Under what conditions does the current generation of the prey dynasty choose to tolerate predation and less than perfect security of its property, rather than to deter predation? How does the security of the prey dynasty's property evolve over generations? What factors determine the accumulation of productive capital in each generation? How does the accumulation of productive capital evolve over generations? And, most importantly, how is the accumulation of productive capital related to the evolution of the security of the prey dynasty's property? One of the main lessons from our analysis is that the relation between the accumulation of capital and the security of property is neither continuous nor monotonic because, even if deterrence is a better choice for the prey than tolerating predation, deterrence is a costly choice.

\section{The Model}

Consider the following dynastic growth model that includes the possibility of repeated interaction between the potential predator dynasty and the prey dynasty. In each period $t$, a new generation of the potential predator dynasty and a new generation of the prey dynasty are born. Each new generation inherits from the previous generation positive wealth endowments, $\omega_{t}$ for the potential predator dynasty and $\Omega_{t}$ for the prey dynasty. In each generation, the security of the prey dynasty's property is determined endogenously by the allocative decisions made by that generation of the potential predator dynasty and the prey dynasty. ${ }^{2}$

\footnotetext{
${ }^{2}$ This analysis takes the identity of the potential predator dynasty and the prey dynasty as given, and it assumes that the predatory interaction is one-sided. The prey dynasty does not attempt to appropriate the resources of the potential predator dynasty. An extended analysis would determine the identity of the potential predator and the prey endogenously. The present analysis also does not explicitly address the possibility that a third party, like government, acts as the proximate enforcer of claims to property. In fact, in situations in which the claimants to property are groups like tribes or nations, third parties typically play no role in enforcing claims to property. Moreover, even if the claimants to property are individuals, third-party enforcement is not the historical basis for secure property. As Vernon Smith (1993, page 170) points out, "property rights ... precede the state ..."
} 
As in our previous models of predation - see Grossman and $\operatorname{Kim}(1995,1996)$ - each generation of the prey dynasty can choose to deter predation. The alternative to deterrence is to tolerate predation and to mitigate its effects. To allow defensive fortifications to be a deterrent to predation, we assume that in each generation the prey dynasty and the potential predator dynasty allocate their endowments in the following sequence:

Out of its endowment, $\Omega_{t}$, generation $t$ of the prey dynasty consumes $C_{t}$ and allocates the rest to productive capital, $K_{t}$, and to defensive fortifications, $G_{t}$, with the constraints $C_{t} \geq 0, K_{t} \geq 0, G_{t} \geq 0$, and $\Omega_{t}=C_{t}+K_{t}+G_{t}$. After observing the allocation of resources by generation $t$ of the prey dynasty, generation $t$ of the potential predator dynasty consumes $c_{t}$ and allocates the rest of its endowment to productive capital, $k_{t}$, and to offensive weapons, $g_{t}$, with the constraints $c_{t} \geq 0, k_{t} \geq 0, g_{t} \geq 0$, and $\omega_{t}=c_{t}+k_{t}+g_{t}{ }^{3}$

We assume, for simplicity, that the resources allocated to either defensive fortifications or offensive weapons are spent in generation $t$ and have no salvage value. We also assume that the productive activities of the two dynasties are independent and that both dynasties get the same constant rate of return from their productive capital. Specifically, generation $t$ of the potential predator dynasty produces $(\alpha-1) k_{t}$ and generation $t$ of the prey dynasty produces $(\alpha-1) K_{t}$, where $\alpha$ is a constant gross productivity parameter larger than one. ${ }^{4}$

At the end of generation $t$, the gross production of generation $t$ of the prey dynasty,

\footnotetext{
${ }^{3}$ This analysis abstracts from collective choice issues. The model treats each generation of each dynasty as a unitary agent that maximizes a single well-defined objective function. Also, in this model, the allocations to productive capital and to either defensive fortifications or offensive weapons are rival uses of a dynasty's resources. The same unit of resource cannot be allocated to more than one use.

"In this setup total production in each generation depends only on the total amount of productive capital. Total production does not depend on the distribution of productive capital between the potential predator dynasty and the prey dynasty. Other specifications of the technology would allow for cooperative production with the two dynasties as owners of complementary resources. With cooperative production, either output would go into a common pool subject to appropriation, as in the models of Hirshleifer $(1991,1995)$ and Skaperdas (1992), or the model would have to include some social arrangement such as a market, as in Grossman (1994, 1995), for determining income claims. Another possibility would be to assume that the two dynasties produce different products and to allow them to have a trading relation as well as the potential for a predatory interaction. Skaperdas and Constantinos Syropoulos (1996) develop a model of predation with trade.
} 
$\alpha K_{t}$, is subject to predation by generation $t$ of the potential predator dynasty. ${ }^{5}$ The fraction of its gross production that the prey dynasty retains in generation $t$ provides a measure of the security of the prey dynasty's property in generation $t$. This fraction depends on the relative allocations in generation $t$ to offensive weapons and defensive fortifications. Specifically, the prey dynasty in generation $t$ retains the fraction $P_{t}$ of its gross production, where

$$
\begin{gathered}
P_{t}= \begin{cases}1-X_{t} & \text { for } 0 \leq X_{t}<1 \\
0 & \text { for } X_{t} \geq 1\end{cases} \\
\text { and } \quad X_{t}=\theta \frac{g_{t}}{G_{t}} .
\end{gathered}
$$

In equation (1), $X_{t}$ measures the offensive strength of the potential predator dynasty relative to the defensive strength of the prey dynasty in generation $t$, where $\theta$ is a constant positive parameter that indicates the effectiveness of offensive weapons against defensive fortifications. Equation (1) implies that $0 \leq P_{t} \leq 1$ and that $P_{t}$ is weakly decreasing in $X_{t}{ }^{6}$

We also allow for the possibility that predation is destructive, by which we mean that the predator gains less from predation than the prey loses. For example, perhaps the predator's gain is subject to deterioration during shipment or the predator's gain needs to be processed to be usable. ${ }^{7}$ Specifically, although the prey dynasty loses the fraction $1-P_{t}$

\footnotetext{
${ }^{5}$ In related models developed in Grossman and $\operatorname{Kim}(1995,1996)$, productive capital, defensive fortifications, and offensive weapons were all subject to predation but output was not subject to predation. In the present setup, output as well as productive capital are subject to predation, but, as explained above, defensive fortifications and offensive weapons are spent.

${ }^{6}$ In this formulation $X_{t}$, is a homogeneous function of degree zero in $g_{t}$ and $G_{t}$ and of degree one in the ratio, $g_{t} / G_{t}$. A more general specification, used by some authors, would be that $X_{t}$ is homogeneous of degree $r$ in the ratio $g_{t} / G_{t}, r>0$. Hirshleifer $(1991,1995)$ interprets $r$ as a "decisiveness" parameter. Note that, although $X_{t}$ is a positive function of $\theta, X_{t}$ could be either a positive or negative function of $r$ depending on whether $g_{t}$ is larger or smaller than $G_{t}$. An even more general specification - see, for example, Grossman (1991) - would be that $X_{t}$ is homogeneous, but not necessarily of degree zero, in $g_{t}$ and $G_{t}$ and that $X_{t}$ is not homogeneous in the ratio $g_{t} / G_{t}$.

${ }^{7}$ Another possibility would be that predation involves violence and destruction. But, given complete information and the absence of stochastic factors, this model does not provide an internal explanation for violence and destruction. Dagobert Brito and Michael Intriligator (1985) address the question of whether conflict is resolved with or without violence and destruction. They emphasize the importance of incomplete information as a cause of violence. In fact, predation in most cases does not involve violence.
} 
of its gross production, the predator dynasty gains only the fraction $(1-\beta)\left(1-P_{t}\right)$ of the prey dynasty's gross production, where $0 \leq \beta \leq 1$. The parameter $\beta$ measures the destructiveness of predation.

The wealth endowments of the next generation of each dynasty depend on the gross production of both dynasties in the current generation and on the results of their predatory interaction. Each generation of the potential predator dynasty bequeaths to the next generation its own gross production plus the amount of the prey dynasty's gross production that it appropriates from the prey dynasty, net of destruction. Thus, the wealth endowment for the generation of the potential predator dynasty born in period $t+1$ is

$$
\omega_{t+1}=\alpha k_{t}+(1-\beta)\left(1-P_{t}\right) \alpha K_{t}
$$

Each generation of the prey dynasty bequeaths to the next generation its own gross production less the amount of its gross production that it loses in the predatory interaction. Thus, the wealth endowment for the generation of the prey dynasty born in period $t+1$ is

$$
\Omega_{t+1}=P_{t} \alpha K_{t}
$$

Each generation of each dynasty gets utility from its own consumption and from the bequest that it leaves to the next generation of its dynasty. ${ }^{8}$ Each generation of each dynasty maximizes the sum of these utilities. Specifically, generation $t$ of the potential

\footnotetext{
${ }^{8}$ For tractability we adopt the specification that each generation gets utility directly from its bequest to the next generation. Models of savings behavior sometimes assume instead that each generation cares directly about either the consumption of the next generation or the utility of the next generation. Either of these alternative specifications would introduce complications that we have chosen to avoid. For example, if the current generation of the predator dynasty cares directly about the utility of the next generation, then it cares indirectly about the consumption of all future generations of the predator dynasty. In this case, even if it could maximize the bequest to the next generation by engaging in predation, the current generation of the predator dynasty would consider the possibility of deferring predation to allow some future generation of the predator dynasty to appropriate from a richer prey. In addition, these alternative specifications would introduce the possibility of a cooperative equilibrium, in which the dynasties would agree to limit their allocations to defensive fortifications and offensive weapons. Under certain conditions the threat of punishments that would reduce the consumption of future generations could sustain such a cooperative equilibrium.
} 
predator dynasty maximizes

$$
v_{t}=u\left(c_{t}\right)+u\left(\omega_{t+1}\right)
$$

where $u^{\prime}(\cdot)>0, u^{\prime}(0)=\infty$, and $u^{\prime \prime}(\cdot)<0$. Similarly, generation $t$ of the prey dynasty maximizes

$$
V_{t}=U\left(C_{t}\right)+U\left(\Omega_{t+1}\right)
$$

where $U^{\prime}(\cdot)>0, U^{\prime}(0)=\infty$, and $U^{\prime \prime}(\cdot)<0$. For simplicity, this formulation abstracts from pure time preference.

\section{Resource Allocation: The Potential Predator}

To analyze this model, we begin by considering the allocation of inherited wealth by generation $t$ of the potential predator dynasty among consumption, $c_{t}$, productive capital, $k_{t}$, and offensive weapons, $g_{t}$. Generation $t$ of the potential predator dynasty chooses $c_{t}, k_{t}$, and $g_{t}$ to maximize $v_{t}$, subject to the constraints $c_{t} \geq 0, k_{t} \geq 0, g_{t} \geq 0$, and $\omega_{t}=c_{t}+k_{t}+g_{t}$. Generation $t$ of the potential predator dynasty takes the allocation of resources by generation $t$ of the prey dynasty as given.

Given $K_{t}$, equation (2.1) implies that the bequest to generation $t+1$ of the potential predator dynasty, $\omega_{t+1}$, is a linear function of $k_{t}$ and $P_{t}$. In addition, given $G_{t}$, equation (1) implies that $P_{t}$ is a linear function of $g_{t}$. Specifically, a unit of productive capital increases the bequest by $\alpha$, and a unit of offensive weapons increases the bequest by $(1-\beta) \frac{\theta}{G_{t}} \alpha K_{t}$. Consequently, generation $t$ of the potential predator dynasty allocates all of its endowment, net of consumption, either to productive capital or to offensive weapons depending on whether or not $\alpha$ is at least as large as $(1-\beta) \frac{\theta}{G_{t}} \alpha K_{t} \cdot{ }^{9}$

This result implies that, if generation $t$ of the prey dynasty has allocated a sufficiently large amount of wealth to defensive fortifications relative to its productive capital - that

\footnotetext{
${ }^{9}$ This result presumes that generation $t$ of the prey dynasty has chosen $G_{t}$ such that either $G_{t}>$ $\theta\left(\omega_{t}-c_{t}\right)$ or $G_{t} \geq(1-\beta) \theta K_{t}$. Otherwise, $P_{t}$ would be zero, and generation $t+1$ of the prey dynasty would receive no bequest. Because we assume that $U^{\prime}(0)=\infty$, generation $t$ of the prey dynasty would not choose this outcome.
} 
is, if $G_{t} \geq(1-\beta) \theta K_{t}$ - then generation $t$ of the potential predator dynasty is completely deterred from allocating its wealth to offensive weapons. In this case, generation $t$ of the potential predator dynasty allocates all of its wealth, net of consumption, to productive capital. Alternatively, if generation $t$ of the prey dynasty has chosen $G_{t}$ such that $G_{t}<(1-\beta) \theta K_{t}$, then generation $t$ of the potential predator dynasty allocates all of its wealth, net of consumption, to offensive weapons and none of its wealth to productive capital. ${ }^{10}$

To solve the complete allocation problem for generation $t$ of the potential predator dynasty, we substitute equation (2.1) into equation (3.1). We then see that, if $G_{t} \geq$ $(1-\beta) \theta K_{t}$, then $v_{t}$ is maximized with

$$
k_{t}=\omega_{t}-c_{t} \text { and } g_{t}=0
$$

and with $c_{t}$ chosen such that

$$
\frac{\partial v_{t}}{\partial c_{t}}=u^{\prime}\left(c_{t}\right)-\alpha u^{\prime}\left(\omega_{t+1}\right)=0
$$

Given condition (4.1), increasing consumption in the current generation decreases the bequest to the next generation by $\alpha$. Condition (4.2) equates the marginal utility of consumption to the marginal cost of consumption, which, with $g_{t}$ equal to zero, equals $\alpha$ times the marginal utility of the bequest. Alternatively, if $G_{t}<(1-\beta) \theta K_{t}$, then $v_{t}$ is maximized with

$$
k_{t}=0 \text { and } g_{t}=\omega_{t}-c_{t}
$$

and with $c_{t}$ chosen such that

$$
\frac{\partial v_{t}}{\partial c_{t}}=u^{\prime}\left(c_{t}\right)-(1-\beta) \frac{\theta}{G_{t}} \alpha K_{t} u^{\prime}\left(\omega_{t+1}\right)=0 .
$$

\footnotetext{
${ }^{10}$ In Grossman and $\operatorname{Kim}(1995,1996)$, we assume that $P_{t}$ is a nonlinear function of $X_{t}$. With this assumption, for some values of $G_{t}$, generation $t$ of the potential predator dynasty would allocate positive amounts of resources both to productive activity and to predatory activity. In the present context in which we want to analyze the accumulation of capital with and without active predation, assuming that $P_{t}$ is a piecewise linear function of $X_{t}$, as in equation (1), simplifies the analysis with little loss of generality.
} 
Given condition (5.1), increasing consumption in the current generation decreases the bequest to the next generation by $(1-\beta) \frac{\theta}{G_{t}} \alpha K_{t}$. Condition (5.2) equates the marginal utility of consumption to the marginal cost of consumption, which, with $k_{t}$ equal to zero, equals $(1-\beta) \frac{\theta}{G_{t}} \alpha K_{t}$ times the marginal utility of the bequest.

To simplify the analysis we assume that the utility function of the potential predator dynasty has the form, $u(\cdot)=\log (\cdot)$. Then, conditions (4.2) and (5.2) imply that, regardless of the choice of $g_{t}$ and $k_{t}$, generation $t$ of the potential predator dynasty chooses

$$
c_{t}=\frac{\omega_{t}}{2}
$$

Substituting equation (6) into conditions (4.1) and (5.1), we see that the allocation to productive capital by generation $t$ of the potential predator dynasty is

$$
k_{t}=\left\{\begin{array}{lll}
\frac{\omega_{t}}{2} & \text { for } & G_{t} \geq(1-\beta) \theta K_{t} \\
0 & \text { for } & G_{t}<(1-\beta) \theta K_{t},
\end{array}\right.
$$

and that that the allocation to offensive weapons by generation $t$ of the potential predator dynasty is

$$
g_{t}=\left\{\begin{array}{lll}
0 & \text { for } & G_{t} \geq(1-\beta) \theta K_{t} \\
\frac{\omega_{t}}{2} & \text { for } & G_{t}<(1-\beta) \theta K_{t}
\end{array}\right.
$$

The simple result that either $k_{t}$ or $g_{t}$ is equal to $c_{t}$ follows from the assumptions that the utility function of the potential predator dynasty is logarithmic, that the production technology is linear, and that $P_{t}$ is a linear function of $g_{t}$.

\section{Resource Allocation: The Prey}

Generation $t$ of the prey dynasty chooses $C_{t}, K_{t}$, and $G_{t}$ to maximize utility as given in equation (3.2), subject to the constraints $C_{t} \geq 0, K_{t} \geq 0, G_{t} \geq 0$, and $\Omega_{t}=C_{t}+K_{t}+G_{t}$. Generation $t$ of the prey dynasty takes into account how its allocations of wealth to defensive fortifications and to productive capital will affect the allocation of wealth to offensive weapons by generation $t$ of the potential predator dynasty. 
To solve the allocation problem for generation $t$ of the prey dynasty we substitute equations (1), (2.2), (8), and $K_{t}=\Omega_{t}-C_{t}-G_{t}$ into equation (3.2). We then find that the utility of generation $t$ of the prey dynasty, $V_{t}$, has at least one local maximum described by

$$
G_{t}=(1-\beta) \theta K_{t}
$$

and

$$
\frac{\partial V_{t}}{\partial C_{t}}=U^{\prime}\left(C_{t}\right)-\alpha U^{\prime}\left(\alpha K_{t}\right)=0
$$

To see that condition (9.1) is necessary for a local maximum, observe that, if and only if $G_{t} \geq(1-\beta) \theta K_{t}$, then $g_{t}=0$ and $P_{t}=1$. Consequently, at $G_{t}=(1-\beta) \theta K_{t}$, given $C_{t}$, an increase in $G_{t}$ would only decrease the prey dynasty's gross production in generation $t$. In addition, at $G_{t}=(1-\beta) \theta K_{t}$ a marginal decrease in $G_{t}$ would result in a discrete increase in $g_{t}$ from zero to $\omega_{t} / 2$ and discrete decreases in $P_{t}$ and in $P_{t} \alpha K_{t}$.

With $G_{t}=(1-\beta) \theta K_{t}$ and $P_{t}=1$, increasing consumption, $C_{t}$, would decrease the bequest to generation $t+1$ of the prey dynasty by $\alpha$. Condition (9.2) says that, with $G_{t}=(1-\beta) \theta K_{t}$, generation $t$ of the prey dynasty chooses its consumption such that the marginal utility of consumption equals $\alpha$ times the marginal utility of the bequest.

We also find that $V_{t}$ can have another local maximum described by

$$
\frac{\partial V_{t}}{\partial G_{t}}=\left(-P_{t} \alpha+\frac{\partial P_{t}}{\partial G_{t}} \alpha K_{t}\right) U^{\prime}\left(P_{t} \alpha K_{t}\right)=0 \quad \text { and } \quad \theta \frac{\omega_{t}}{2}<G_{t}<(1-\beta) \theta K_{t}
$$

and

$$
\frac{\partial V_{t}}{\partial C_{t}}=U^{\prime}\left(C_{t}\right)-P_{t} \alpha U^{\prime}\left(P_{t} \alpha K_{t}\right)=0
$$

If $\theta \frac{\omega_{t}}{2}<G_{t}<(1-\beta) \theta K_{t}$, then a marginal change in $G_{t}$ would affect the bequest to generation $t+1$ of the prey dynasty in two ways: An increase in $G_{t}$ would increase $P_{t}$ and would decrease $K_{t}$, thereby changing the amount of bequest by $-P_{t} \alpha+\frac{\partial P_{t}}{\partial G_{t}} \alpha K_{t}$. 
If $-P_{t} \alpha+\frac{\partial P_{t}}{\partial G_{t}} \alpha K_{t}>0$ for all values of $G_{t}$ that satisfy $\theta \frac{\omega_{t}}{2} \leq G_{t}<(1-\beta) \theta K_{t}$, then there exists no local maximum that satisfies condition (10.1). Otherwise, conditions (10.1) and (10.2) describe a local maximum. At the value of $G_{t}$ that satisfies condition (10.1), the positive marginal effect on the bequest to generation $t+1$ from increasing $G_{t}$ and increasing $P_{t}$ exactly equals the negative marginal effect from increasing $G_{t}$ and decreasing $K_{t}$.

With $G_{t}<(1-\beta) \theta K_{t}$ and $P_{t}<1$, given $G_{t}$, increasing $C_{t}$ would decrease the bequest to generation $t+1$ of the prey dynasty by $P_{t} \alpha$. Condition (10.2) says that, with $G_{t}<(1-\beta) \theta K_{t}$, generation $t$ of the prey dynasty chooses its consumption such that the marginal utility of consumption equals $P_{t} \alpha$ times the marginal utility of the bequest. ${ }^{11}$

If there is no local maximum that satisfies conditions (10.1) and (10.2), then the local maximum described by conditions (9.1) and (9.2) is also the global maximum. If there are two local maxima, then generation $t$ of the prey dynasty allocates its wealth by comparing the value of $V_{t}$ associated with conditions (9.1) and (9.2) to the value of $V_{t}$ associated with conditions (10.1) and (10.2).

\section{The Security of the Prey's Property}

Denote the value of $V_{t}$ associated with conditions (9.1) and (9.2) by $V_{t}^{*}$ and the value of $V_{t}$ associated with conditions (10.1) and (10.2) by $V_{t}^{\circ}$. If and only if $V_{t}^{*} \geq V_{t}^{\circ}$, generation $t$ of the prey dynasty prefers to deter predation with a large allocation to defensive fortifications rather than to tolerate predation and to mitigate its effects with a smaller allocation to defensive fortifications. In this case, we denote the allocations by generation $t$ of the prey dynasty to consumption, productive capital, and defensive fortifications as $C_{t}^{*}, K_{t}^{*}$, and $G_{t}^{*}$, respectively.

If $G_{t}$ equals $G_{t}^{*}$, then generation $t$ of the potential predator dynasty allocates

\footnotetext{
${ }^{11}$ As noted above, generation $t$ of the prey dynasty would not choose $G_{t} \leq \theta \frac{\omega_{t}}{2}$ because such a small allocation to defensive fortifications would imply $P_{t}=\Omega_{t+1}=0$. Because we assumed $U^{\prime}(0)=\infty$, an allocation of wealth such that $P_{t}=\Omega_{t+1}=0$ can never satisfy condition (10.2).
} 
none of its wealth to offensive weapons and allocates all of its wealth equally to consumption and to productive capital. In this case, there is no predation in generation $t$. With no predation, $P_{t}$ equals one. In other words, the prey dynasty's property in generation $t$ is fully secure.

Alternatively, if and only if $V_{t}^{*}<V_{t}^{\circ}$, generation $t$ of the prey dynasty prefers to tolerate predation rather than to deter predation. In this case, we denote the allocations by generation $t$ of the prey dynasty to consumption, productive capital, and defensive fortifications as $C_{t}^{\circ}, K_{t}^{\circ}$, and $G_{t}^{\circ}$, respectively.

If $G_{t}$ equals $G_{t}^{\circ}$, which is smaller than $G_{t}^{*}$, then generation $t$ of the potential predator dynasty allocates all of its wealth, net of consumption, to offensive weapons and allocates none to productive capital. In this case, there is active predation in generation $t$. With active predation $P_{t}$ is less than one. In other words, the prey dynasty's property in generation $t$ is less than fully secure.

To simplify the analysis we assume that the utility function of the prey dynasty, like the utility function of the potential predator dynasty, has the form, $U(\cdot)=\log (\cdot)$. Given this assumption, $C_{t}^{*}, K_{t}^{*}$, and $G_{t}^{*}$ satisfy

$$
\begin{aligned}
& G_{t}^{*}=(1-\beta) \theta K_{t}^{*} \\
& K_{t}^{*}=C_{t}^{*} \\
& \Omega_{t}=C_{t}^{*}+K_{t}^{*}+G_{t}^{*}
\end{aligned}
$$

and $C_{t}^{\circ}, K_{t}^{\circ}$, and $G_{t}^{\circ}$ satisfy

$$
\begin{aligned}
& G_{t}^{\circ}=\left\{G_{t} \mid P_{t}=\frac{\partial P_{t}}{\partial G_{t}} K_{t}^{\circ}\right\} \\
& K_{t}^{\circ}=C_{t}^{\circ} \\
& \Omega_{t}=C_{t}^{\circ}+K_{t}^{\circ}+G_{t}^{\circ}
\end{aligned}
$$

where $P_{t}=1-\theta \frac{\omega_{t} / 2}{G_{t}}$ and $\frac{\partial P_{t}}{\partial G_{t}}=\theta \frac{\omega_{t} / 2}{G_{t}^{2}}$.

Equations (11.1) and (11.2) imply that each generation of the prey dynasty, whether it deters predation or tolerates predation, allocates its wealth, net of defensive fortifica- 
tions, equally to consumption and productive capital. The implication that the allocation of wealth, net of defensive fortifications, by generation $t$ of the prey dynasty between consumption and productive capital is independent of the security of the prey dynasty's property follows from the assumption that the utility function of the prey dynasty is logarithmic. ${ }^{12}$ The further implication that the allocations to consumption and productive capital are equal follows from the additional assumption that the production technology is linear.

From equations (11.2) we can infer how generation $t$ of the prey dynasty allocates its wealth, given that generation $t$ of the prey dynasty chooses to tolerate predation. Most importantly, equations (11.2) imply that $G_{t}^{\circ}$ depends positively on $\omega_{t}$, the inherited wealth of generation $t$ of the potential predator dynasty. Because the allocation to offensive weapons by generation $t$ of the potential predator dynasty is proportionate to $\omega_{t}$, the larger is $\omega_{t}$ the larger is the marginal return to generation $t$ of the prey dynasty from allocating resources to defensive fortifications. In addition, because $G_{t}^{\circ}$ depends positively on $\omega_{t}, C_{t}^{\circ}$ and $K_{t}^{\circ}$ depend negatively on $\omega_{t}$. For a given value of $\Omega_{t}$, a larger allocation to defensive fortifications implies smaller allocations to consumption and productive capital.

But, $G_{t}^{o}$ increases less than proportionately to any increase in $\omega_{t}$. If generation $t$ of the prey dynasty faces larger values of $\omega_{t}$ and $g_{t}$, then generation $t$ of the prey dynasty chooses to tolerate a smaller value for $P_{t}$. To understand this result, recall that an increase in $G_{t}$ affects the bequest received by generation $t+1$ both positively by increasing $P_{t}$ and negatively by decreasing $K_{t}$. If $G_{t}$ were to increase proportionately to an increase in $\omega_{t}$, then the positive marginal effect on the bequest from increasing $P_{t}$ would be smaller than the negative marginal effect from decreasing $K_{t}$. Using equations $(1),(8),(11.1)$, and (11.2), we find that generation $t$ of the prey dynasty allocates its

\footnotetext{
${ }^{12}$ With a logarithmic utility function, the elasticity of marginal utility is constant and equals minus one. More generally, the allocation of wealth, net of defensive fortifications, by generation $t$ of the prey dynasty between consumption and productive capital would depend on $P_{t}$, and the direction of this effect would depend on whether the elasticity of marginal utility were larger or smaller than minus one.
} 
wealth such that

$$
P_{t}= \begin{cases}1 & \text { if and only if } V_{t}^{*} \geq V_{t}^{\circ} \\ P\left(\frac{\Omega_{t}}{\omega_{t}}, \theta\right)<1 & \text { if and only if } V_{t}^{*}<V_{t}^{\circ},\end{cases}
$$

where $\frac{\partial P}{\partial\left(\Omega_{t} / \omega_{t}\right)}>0$ and $\frac{\partial P}{\partial \theta}<0$.

An important implication of the preceding discussion is that, if generation $t$ of the prey dynasty chooses to tolerate predation, then the larger is $\omega_{t}$ relative to $\Omega_{t}$, the larger is $G_{t}$ relative to $\Omega_{t}$. Thus, the larger is $\omega_{t}$ relative to $\Omega_{t}$, both the smaller is $K_{t}$ relative to $\Omega_{t}$ and the smaller is $P_{t}$.

The positive relation between $K_{t} / \Omega_{t}$, the fraction of inherited wealth that generation $t$ of the prey dynasty allocates to productive capital, and $P_{t}$, the security of the prey dynasty's property in generation $t$, does not reflect a direct effect of $P_{t}$ on $K_{t} / \Omega_{t}$. As noted above, the assumption that the utility function of the prey dynasty is logarithmic neutralizes this direct effect, which in general could be either positive or negative. Rather the positive relation between $K_{t} / \Omega_{t}$ and $P_{t}$ results from the fact that a larger ratio $\omega_{t} / \Omega_{t}$ causes generation $t$ of the prey dynasty to allocate more of its wealth to defensive fortifications, but not enough more to prevent a decrease in the security of its property.

We now can derive the conditions under which generation $t$ of the prey dynasty chooses to tolerate predation and less than perfect security of its property, rather than to deter predation. As we have seen, generation $t$ of the prey dynasty compares $V_{t}^{*}$ to $V_{t}^{\circ}$ in order to decide whether or not to deter predation. Combining equations (11.1), (11.2), and (12) with equation (3.2) we find that

$$
V_{t}^{*} \geq V_{t}^{\circ} \text { if and only if } F\left(\frac{\Omega_{t}}{\omega_{t}}, \theta, \beta\right) \geq 0,
$$

where $\frac{\partial F}{\partial\left(\Omega_{t} / \omega_{t}\right)}<0, \quad \frac{\partial F}{\partial \theta}<0$ for small values of $\theta$ and $\frac{\partial F}{\partial \theta}>0$ for large values of $\theta$, and $\frac{\partial F}{\partial \beta}>0$.

Given the form of the function $F\left(\Omega_{t} / \omega_{t}, \theta, \beta\right)$, equation (13) implies that, if and only if $\Omega_{t} / \omega_{t}$ is large enough, then generation $t$ of the prey dynasty tolerates predation. 
This result obtains because, if $\Omega_{t} / \omega_{t}$ were small and generation $t$ the prey dynasty were to tolerate predation, then $P_{t}$ would be small. In this situation, it would be better for generation $t$ of the prey dynasty to deter predation, even though deterrence requires a larger allocation to defensive fortifications.

Equation (13) also implies that, for a given value of $\Omega_{t} / \omega_{t}$, generation $t$ of the prey dynasty is more likely to deter predation the smaller is $\theta$ and the larger is $\beta$. The smaller is $\theta-$ that is, the less effective are offensive weapons against defensive fortifications then the easier it is for each generation of the prey dynasty to deter predation. The larger is $\beta$, then the smaller is the potential predator dynasty's gain from predation for a given value of $P_{t}$, and again the easier it is for each generation of the prey dynasty to deter predation. ${ }^{13}$

\section{The Evolution from Predation to Deterrence}

We saw in the previous section that the endowments of inherited wealth of the two dynasties in generation $t$ help to determine the dynasties' allocations to productive capital in generation $t$ and the security of the prey dynasty's property in generation $t$. Also, equations (2.1) and (2.2) say that the dynasties' allocations to productive capital in generation $t$ and the security of the prey dynasty's property in generation $t$ determine the endowments of inherited wealth in generation $t+1$. Thus, inherited wealth, productive capital, and the security of the prey dynasty's property are inter-related along the path of evolution of the dynasties.

Most importantly, the endowments of inherited wealth in generation $t+1$ in general will be different from the endowments of inherited wealth in generation $t$. Thus, the allocations to productive capital and the security of the prey dynasty's property also will be different in generation $t+1$ from generation $t$. It is even possible that from one

\footnotetext{
${ }^{13}$ In this model, because $P_{t}$ is piecewise linear in $X_{t}$, generation $t$ of the prey dynasty also would choose to deter predation if $\theta$ were very large. In Grossman and Kim (1996), we saw that, if $P_{t}$ is a smooth concave function of $X_{t}$, then, even with a very large value of $\theta$, the potential predator allocates a positive amount of resources to predatory activity.
} 
generation to another the prey dynasty switches from tolerating predation to deterring predation. This section studies the evolution of the dynamical system.

Consider the following historical examples: The Vikings, who had been preying upon the Normandy area in the 10th century, ended up settling down in that area and became producers. Also, many tribes on the medieval Chinese border who lived mainly by plundering Chinese villages turned themselves into producers eventually. Our model shows that these phenomena are explicable as part of the endogenous inter-related evolution of endowments of inherited wealth and the resulting change over generations from predation to deterrence.

Combined with equations (7), (11.1), (11.2), and (12), equations (2.1) and (2.2) imply that generation $t$ of the prey dynasty bequeaths to generation $t+1$ of the prey dynasty

$$
\Omega_{t+1}= \begin{cases}\alpha K_{t}^{*} & \text { for } F\left(\frac{\Omega_{t}}{\omega_{t}}, \theta, \beta\right) \geq 0 \\ P\left(\frac{\Omega_{t}}{\omega_{t}}, \theta\right) \alpha K_{t}^{\circ} & \text { for } F\left(\frac{\Omega_{t}}{\omega_{t}}, \theta, \beta\right)<0\end{cases}
$$

and that generation $t$ of the potential predator dynasty bequeaths to generation $t+1$ of the potential predator dynasty

$$
\omega_{t+1}= \begin{cases}\alpha k_{t} & \text { for } \quad F\left(\frac{\Omega_{t}}{\omega_{t}}, \theta, \beta\right) \geq 0 \\ (1-\beta)\left[1-P\left(\frac{\Omega_{t}}{\omega_{t}}, \theta\right)\right] \alpha K_{t}^{\circ} & \text { for } F\left(\frac{\Omega_{t}}{\omega_{t}}, \theta, \beta\right)<0 .\end{cases}
$$

Equations (14.1) and (14.2) say that, if generation $t$ of the prey dynasty deters predation, then the inherited wealth of each dynasty in generation $t+1$ depends only on the gross production of that dynasty in generation $t$. But, if generation $t$ of the prey dynasty tolerates predation, then the inherited wealth of generation $t+1$ of both the prey dynasty and the predator dynasty depends on the gross production of generation $t$ of the prey dynasty and on the security of the prey dynasty's property in generation $t$.

By calculating closed form solutions for $K_{t}^{*}, K_{t}^{\circ}$, and $P\left(\frac{\Omega_{t}}{\omega_{t}}, \theta\right)$, we can show that 
the distribution of wealth, $\Omega_{t} / \omega_{t}$, evolves according to the following path:

$$
\frac{\Omega_{t+1}}{\omega_{t+1}}= \begin{cases}\frac{2}{2+(1-\beta) \theta} \frac{\Omega_{t}}{\omega_{t}} & \text { for } F\left(\frac{\Omega_{t}}{\omega_{t}}, \theta, \beta\right) \geq 0 \\ \frac{\sqrt{1+\frac{16}{\theta}} \frac{\Omega_{t}}{\omega_{t}}-3}{4(1-\beta)} & \text { for } F\left(\frac{\Omega_{t}}{\omega_{t}}, \theta, \beta\right)<0 .\end{cases}
$$

Equation (15) says that $\Omega_{t} / \omega_{t}$ decreases over generations whether the current generation of the prey dynasty tolerates or deters predation. With the prey dynasty deterring predation, $\Omega_{t} / \omega_{t}$ decreases over generations because each generation of the prey dynasty allocates a positive fraction of its inherited wealth to defensive fortifications and, hence, allocates a smaller fraction of inherited wealth to productive capital than the predator dynasty. With the prey dynasty tolerating predation, $\Omega_{t} / \omega_{t}$ decreases over generations because each generation of the prey dynasty allocates a small fraction of its inherited wealth to defensive fortifications relative to the fraction of its inherited wealth that the predator dynasty allocates to offensive weapons.

To understand the evolution of the dynamical system, start by imagining a hypothetical world with only one dynasty. In this world there is no potential predation, because there is no potential predator. Suppose that each generation maximizes utility as given by equation (3.2) with $\Omega_{t+1}=\alpha K_{t}$ and $u(\cdot)=\log (\cdot)$. Accordingly, each generation allocates one half of its inherited wealth to consumption and allocates the other half to productive capital. Over generations, if $\alpha>2$, then the inherited wealth of this dynasty grows large.

Now, suppose a new dynasty comes into this world. This new dynasty, whose initial wealth, $\omega_{0}$, is very small, is a potential predator. The original dynasty, which has grown wealthy, is its prey.

Because $\Omega_{0} / \omega_{0}$ is large, $F\left(\frac{\Omega_{0}}{\omega_{0}}, \theta, \beta\right)$ is negative. Thus, the first generation of the prey dynasty that faces a potential predator tolerates predation. Nevertheless, because $\omega_{0}$ is small, $P_{0}$ is close to one. In other words, because the predator dynasty initially has little wealth, the prey dynasty's property remains highly secure.

Equation (15) implies that the relative inherited wealth of the dynasties in the next 
generation will be such that $\frac{\Omega_{1}}{\omega_{1}}<\frac{\Omega_{0}}{\omega_{0}}$. Accordingly, assuming that $F\left(\frac{\Omega_{1}}{\omega_{1}}, \theta, \beta\right)<0$, the prey dynasty's property in generation one will be less secure than in generation zero. As long as $F\left(\frac{\Omega_{t}}{\omega_{t}}, \theta, \beta\right)<0$, the ratio of the prey dynasty's inherited wealth to the potential predator dynasty's inherited wealth continually decreases and so does the security of the prey dynasty's property.

Because the value of the function $F(\cdot)$ depends negatively on $\Omega_{t} / \omega_{t}$, and because $\Omega_{t} / \omega_{t}$ continually decreases over generations, sooner or later the relative inherited wealth of the dynasties will be such that $F\left(\frac{\Omega_{t}}{\omega_{t}}, \theta, \beta\right)$ is nonnegative. Let $s$ be the minimum value of $t$ such that $F\left(\frac{\Omega_{t}}{\omega_{t}}, \theta, \beta\right) \geq 0$. Equation (15) implies that $\frac{\Omega_{s}}{\omega_{s}}<\frac{\Omega_{s-1}}{\omega_{s-1}}$. Thus, as $\Omega_{t} / \omega_{t}$ keeps decreasing, eventually a generation of the prey dynasty will choose to deter predation.

As soon as a generation of the prey dynasty chooses to deter predation, the property of the prey dynasty becomes perfectly secure. Thus, $P_{t}$ is the lowest in generation $s-1$, which is the last generation that chooses to tolerate predation. From generation $s-1$ to generation $s, P_{t}$ jumps up discretely to one. Generation $s$ is the first generation in which the security of the prey dynasty's property would be so low if that generation of the prey dynasty were to tolerate predation that the prey dynasty in that generation is better off increasing its allocation to defensive fortifications sufficiently to deter predation, even though this increased allocation to defensive fortifications implies that less wealth is allocated to consumption and to productive capital.

Because $\Omega_{t} / \omega_{t}$ continues to decrease even after the prey dynasty chooses to deter predation, the value of the function $F(\cdot)$ continues to decrease. Thus, in the absence of exogenous shocks to the value of the function $F(\cdot)$, this predator dynasty never again preys on this prey dynasty. ${ }^{14}$

\footnotetext{
${ }^{14}$ The fact that $\Omega_{t} / \omega_{t}$ continually decreases does not imply that the prey dynasty grows at a negative rate. If $\alpha>2+(1-\beta) \theta$, then the prey dynasty's inherited wealth grows even if the prey dynasty is allocating to defensive fortifications enough of its wealth to deter predation. But, as $\Omega_{t} / \omega_{t}$ continues to decrease, the prey dynasty will eventually become poorer than the potential predator dynasty. Because the
} 


\section{The Accumulation of Productive Capital}

In section 4, we saw that the dynasties' allocations to productive capital in each generation depend on the relative inherited wealth of the dynasties in that generation. The analysis in section 5 showed how the relative inherited wealth of the dynasties evolves over generations. In this section, we study the accumulation of productive capital by the prey dynasty. In particular, we are interested in seeing how the rate of growth of productive capital evolves over generations and how this evolution is related to the evolution of the security of prey dynasty's property.

To see how the prey dynasty's productive capital evolves from generation to generation, we calculate first the ratio of the prey dynasty's productive capital to its inherited wealth in generation $t$. Solving equations (11.1) simultaneously, we get

$$
\frac{K_{t}^{*}}{\Omega_{t}}=\frac{1}{2+(1-\beta) \theta} .
$$

Also, solving equations (11.2) simultaneously, we get

$$
\frac{K_{t}^{\circ}}{\Omega_{t}}=\frac{1}{2}\left[1-\frac{G_{t}^{\circ}}{\Omega_{t}}\right]=K^{\circ}\left(\frac{\Omega_{t}}{\omega_{t}}, \theta\right),
$$

where $\frac{\partial K^{\circ}}{\partial \Omega_{t} / \omega_{t}}>0$ and $\frac{\partial K^{\circ}}{\partial \theta}<0$. Equation (16.1) says that, if generation $t$ of the prey dynasty chooses to deter predation, then the fraction of its inherited wealth that this generation of the prey dynasty allocates to productive capital is independent of the ratio $\Omega_{t} / \omega_{t}$. But, if generation $t$ of the prey dynasty chooses to tolerate predation, then the fraction of its inherited wealth that this generation of the prey dynasty allocates to productive capital is positively related to $\Omega_{t} / \omega_{t}$.

From equation (14.1) we know that $\Omega_{t+1}$ is proportionate to $K_{t}$ and that the factor of proportionality is the product of $\alpha$ and $P_{t}$. Also, from equation (15) we know that $\Omega_{t+1} / \omega_{t+1}$ is positively related to $\Omega_{t} / \omega_{t}$, and from equation (12) we know that, if

equilibrium interaction between the two dynasties depends on $\Omega_{t} / \omega_{t}$, this development raises the following question: Would the prey-predator relation reverse itself when the prey dynasty becomes poorer than the potential predator dynasty? The present model does not address this issue. 
$P_{t}<1$, then $P_{t}$ is positively related to $\Omega_{t} / \omega_{t}$. Therefore, by substituting equations (12), (14.1), and (15) into equations (16.1) and (16.2) we can show that the evolution of the prey dynasty's productive capital is described by

$$
\frac{K_{t+1}}{K_{t}}=\left\{\begin{array}{lll}
\frac{\alpha}{2+(1-\beta) \theta} & \text { for } & F\left(\frac{\Omega_{t}}{\omega_{t}}, \theta, \beta\right) \geq 0 \\
\alpha R\left(\frac{\Omega_{t}}{\omega_{t}}, \theta\right)>\frac{\alpha}{2+(1-\beta) \theta} & \text { for } & F\left(\frac{\Omega_{t}}{\omega_{t}}, \frac{A}{\alpha}, \theta\right)<0
\end{array}\right.
$$

where $\frac{\partial R}{\partial\left(\Omega_{t} / \omega_{t}\right)}>0$ and $\frac{\partial R}{\partial \theta}<0$.

Equation (17) says that, as long as the prey dynasty tolerates predation, the rate of accumulation of the prey dynasty's productive capital, $K_{t+1} / K_{t}$, is positively related to $\Omega_{t} / \omega_{t}$. This result obtains because the allocation of wealth to productive capital by any generation of the prey dynasty not only depends positively on its own inherited wealth, but, as explained above, also depends negatively on the potential predator's inherited wealth. We also know, from equation (15), that $\Omega_{t} / \omega_{t}$ decreases over generations. Thus, equation (17) and equation (15) together imply that, as long as the prey dynasty tolerates predation, the rate of accumulation of the prey's productive capital decreases over generations as the inherited wealth of the prey dynasty decreases relative to the inherited wealth of the predator dynasty.

As $\Omega_{t} / \omega_{t}$ decreases over generations, the security of the prey dynasty's property decreases as well. Thus, as long as the prey dynasty tolerates predation, the security of the prey dynasty's property and the rate of accumulation of the prey dynasty's productive capital decrease together from generation to generation.

As we have seen, eventually a generation of the prey dynasty finds that with predation its property would be so insecure that it is better off increasing its defensive fortifications sufficiently to deter predation. Equation (17) also says that, when the prey dynasty deters predation, the rate of accumulation of its productive capital becomes independent of $\Omega_{t} / \omega_{t}$. This result obtains because each generation of the prey dynasty that deters predation allocates the same fraction of its inherited wealth to productive capital. Thus, if the prey 
dynasty deters predation, then the rate of accumulation of the prey dynasty's productive capital is the same as the growth rate of the prey dynasty's wealth, which, in turn, is constant because the production technology is homogeneous of degree one in productive capital.

Most importantly, equation (17) implies that, although the rate of accumulation of the prey dynasty's productive capital decreases together with the security of the prey dynasty's property when the prey dynasty is tolerating predation, the relation between the rate of accumulation of the prey dynasty's productive capital and the security of the prey dynasty's property in general is neither continuous nor monotonic. Specifically, the rate of accumulation of the prey dynasty's productive capital does not increase when the prey dynasty finally begins to deter predation and its property becomes fully secure. On the contrary, generations of the prey dynasty that choose to deter predation accumulate productive capital at a slower rate than the preceding generations that tolerated predation. This result obtains because deterrence requires a large allocation of inherited wealth to defensive fortifications. ${ }^{15}$

An interesting implication of this model for empirical research is that the rate of accumulation of capital and the security of property are positively related only for generations of the prey dynasty that tolerate predation. Thus, if we wanted to implement the model empirically and to estimate the relation between $K_{t+1} / K_{t}$ and $P_{t}$, assuming that we could measure $P_{t}$, then we should separate observations in which predation is tolerated from observations in which predation is deterred. Because the theory implies that the relation between $K_{t+1} / K_{t}$ and $P_{t}$ is discontinuous, if we did not separate observations in which predation is tolerated from observations in which predation is deterred, then we would obtain a misleading estimate of the relation between $K_{t+1} / K_{t}$ and $P_{t}$. In fact, because the

\footnotetext{
${ }^{15}$ The rate of accumulation of productive capital by both dynasties taken together increases when the prey dynasty begins to deter predation, because the potential predator dynasty then begins to accumulate productive capital. But, the rate of accumulation of productive capital by both dynasties taken together is less than the rate of accumulation of productive capital by past generations of the prey dynasty.
} 
theory also implies that the relation between $K_{t+1} / K_{t}$ and $P_{t}$ is not monotonic, a simple correlation analysis might lead to the false inference that $K_{t+1} / K_{t}$ and $P_{t}$ are always negatively related.

\section{Summary}

This paper incorporates the economic theory of predation into the theory of economic growth. A central idea is that the security of property and the accumulation of productive capital both are endogenous in the process of economic growth.

The analytical framework is a dynamic general-equilibrium model of the interaction between two dynasties, one of which is a potential predator and the other is its prey. Each generation of each dynasty has to decide how to allocate its endowment of inherited wealth not only to consumption and productive capital, as in standard growth models, but also to either defensive fortifications or offensive weapons. Productive capital forms the basis for accumulation of wealth, but in each generation predation can cause both the destruction of wealth and a redistribution of wealth from the prey dynasty to the predator dynasty.

In this model the current generation of the prey dynasty can choose to allocate a large enough fraction of its inherited wealth to defensive fortifications to deter predation. Alternatively, the current generation of the prey dynasty can choose to tolerate predation and to allocate only enough of its inherited wealth to defensive fortifications to mitigate the effects of predation.

We found that, if the current wealth of the potential predator dynasty is small relative to the current wealth of the prey dynasty, then the current generation of the prey dynasty will choose to tolerate predation rather than to deter predation. We also found that over generations the security of the prey dynasty's property and the rate of accumulation of the prey dynasty's productive capital both steadily decrease, while the inherited wealth of the predator dynasty grows relative to the inherited wealth of the prey dynasty. The security of the prey dynasty's property decreases because the increasing relative wealth of the predator 
dynasty causes the predator dynasty's allocation to offensive weapons to increase relative to the prey dynasty's allocation to defensive fortifications. The rate of accumulation of the prey dynasty's productive capital decreases for two reasons: First, the increasing relative wealth of the predator dynasty causes the prey dynasty to allocate an increasing fraction of its inherited wealth to defensive fortifications and a decreasing fraction of its inherited wealth to productive capital. Second, the decreasing security of the prey dynasty's property causes the inherited wealth of the prey dynasty to increase less rapidly than the productive capital of the prey dynasty.

As the wealth of the predator dynasty continues to grow relative to the wealth of the prey dynasty, eventually a generation of the prey dynasty will find that with predation its property would be so insecure that it is better off increasing its defensive fortifications sufficiently to deter predation. Starting with this generation, the wealth of the prey dynasty becomes perfectly secure. But, importantly, the relation between the security of the prey dynasty's property and its accumulation of productive capital is neither continuous nor monotonic. Generations of the prey dynasty that choose to deter predation, even though their property is perfectly secure, accumulate productive capital more slowly than the preceding generations that tolerated predation. This result obtains because deterrence requires a large allocation of inherited wealth to defensive fortifications. Even if deterrence becomes a better choice for the prey than tolerating predation, deterrence is a costly choice. 


\section{References}

Alesina, Alberto and Rodrik, Dani. "Distributive Politics and Economic Growth," Quarterly Journal of Economics, 109, May 1994, 465-490.

Brito, Dagobert and Intriligator, Michael. "Conflict, War, and Redistribution," American Political Science Review, 79, 1985, 943-957.

Grossman, Herschel I. "A General Equilibrium Model of Insurrections," American Economic Review, 81, September 1991, 912-921.

Grossman, Herschel I. "Production, Appropriation, and Land Reform," American Economic Review, 84, June 1994, 705-712.

Grossman, Herschel I. "Robin Hood and the Redistribution of Property Income," European Journal of Political Economy, 11, 1995, forthcoming.

Grossman, Herschel I. and Kim, Minseong. "Swords or Plowshares? A Theory of the Security of Claims to Property," Journal of Political Economy, 103, December 1995, $1275-1288$.

Grossman, Herschel I. and Kim, Minseong. "Predation and Production," in Michelle R. Garfinkel and Stergios Skaperdas, eds., The Political Economy of Conflict and Appropriation. New York: Cambridge University Press, 1996.

Hirshleifer, Jack. "The Paradox of Power," Economics and Politics, 3, November 1991, $177-200$.

Hirshleifer, Jack. "Anarchy and Its Breakdown," Journal of Political Economy, 103, February $1995,26-52$.

Jones, Gwyn. A History of the Vikings. New York: Oxford University Press, 1968.

Keefer, Philip and Knack, Stephen. "Institutions and Economic Performance: CrossCountry Tests Using Alternative Institutional Measures," Economics and Politics, 1995 , forthcoming.

Lattimore, Owen. Nomads and Commissars: Mongolia Revisited. New York: Oxford 
University Press, 1992.

Perotti, Roberto. "Income Distribution, Politics, and Growth," American Economic Review, 82, May 1992, 311-316.

Skaperdas, Stergios. "Cooperation, Conflict, and Power in the Absence of Property Rights," American Economic Review, 82, September 1992, 720-739.

Skaperdas, Stergios and Syropoulos, Constantinos. "Competitive Trade with Conflict," in Michelle R. Garfinkel and Stergios Skaperdas, eds., The Political Economy of Conflict and Appropriation. New York: Cambridge University Press, 1996.

Smith, Adam. The Wealth of Nations. 1776; reprinted, New York: The Modern Library, 1937.

Smith, Vernon L. "Humankind in History: Economy, Ecology, and Institutions," in Terry L. Anderson and Randy T. Simmons, eds., The Political Economy of Customs and Culture: Informal Solutions to the Commons Problem. Lanham, Maryland: Rowman and Littlefield, 1993. 